\title{
Identifying and Overcoming Barriers to Climate Change Adaptation in the Seychelles
}

\author{
Daniel Etongo, Vincent Amelie, Angelique Pouponneau, and \\ Walter Leal Filho
}

\section{Contents}

Introduction: The Vulnerability of Small Island Developing States to Climate Change ... . . 2676

Climatic and Non-climatic Induced Vulnerabilities in the Seychelles ................ 2677

An Overview of Adaptation Measures in the Seychelles .......................... 2681

Hard Engineering Techniques .......................................... 2681

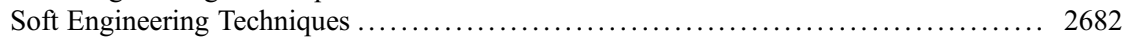

Barriers to Climate Change Adaptation in the Seychelles .......................... 2686

Options for Overcoming Adaptation Barriers in the Seychelles ...................... 2688

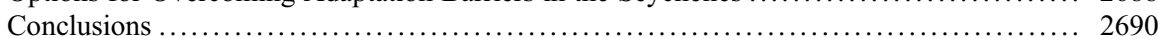

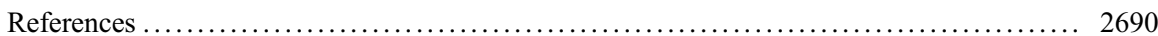

This chapter was previously published non-open access with exclusive rights reserved by the Publisher. It has been changed retrospectively to open access under a CC BY 4.0 license and the copyright holder is "The Author(s)". For further details, please see the license information at the end of the chapter.

D. Etongo $(\square)$

James Michel Blue Economy Research Institute, University of Seychelles, Victoria, Seychelles e-mail: Daniel.Etongo@unisey.ac.sc

\section{Amelie}

Seychelles Meteorological Authority (SMA), Mahé, Seychelles e-mail: v.amelie@meteo.gov.sc

A. Pouponneau

Seychelles' Conservation and Climate Adaptation Trust (SeyCCAT), Mahé, Seychelles e-mail: ceo@seyccat.org

W. L. Filho

Research and Transfer Centre "Sustainable Development and Climate Change Management" Hamburg University of Applied Sciences, Hamburg, Germany

e-mail: walter.leal2@haw-hamburg.de 


\section{Abstract}

As a Small Island Developing State (SIDS), Seychelles is quite vulnerable to the impacts of climate change, and adaptation is considered a national priority. Despite efforts to enhance its adaptive capacity, a number of barriers still hamper the adaptation process such as fragile institutions and inadequate governance to climate change, financial and human resource capacity constraints, and limited scientific knowledge and understanding of how climate change affects the country. A key barrier to climate change adaptation in the Seychelles is called "remote" or "legacy" barriers - linked to land use decisions made five decades ago during which wetlands were reclaimed for property development. Therefore, $80 \%$ of Seychelles' critical infrastructures are located on the coastline and are exposed to floods, erosion, and sea level rise. Additionally, the pros and cons of hard and soft adaptation interventions in the Seychelles ranging from rock armoring, retaining wall, groynes to ecosystem-based adaptation actions such as timber piling, beach nourishment, dune management, rainwater harvesting, and mangrove and coral restoration are assessed with recommendations on the way forward. In other words, this chapter provides some examples of actions and strategies that may assist the island nations to improve on adaptation actions. An example that addresses partly the financial constrain is the Seychelles' Conservation and Climate Adaptation Trust (SeyCCAT) that provide funding for medium- and large-scale project in the Seychelles since 2015.

\section{Keywords}

Climate change $\cdot$ Limits to adaptation $\cdot$ Vulnerability $\cdot$ SeyCCAT $\cdot$ Seychelles

\section{Introduction: The Vulnerability of Small Island Developing States to Climate Change}

Small Island Developing States (SIDS) are generally considered highly vulnerable to climate change, partly because they suffer from similar problems in relation to their landmasses, remoteness, and exposure to natural hazards (Scandurra et al. 2018). As far back as 1992, the United Nations Conference on Environment and Development (UNCED) was the first to recognize SIDS as a distinct group of fragile nations when it stated:

SIDS, and islands supporting small communities are a special case both for environment and development. They are ecologically fragile and vulnerable. Their small size, limited resources, geographic dispersion and isolation from markets, place them at a disadvantage economically and prevent economies of scale. UNCED (1992)

As such, SIDS are generally considered highly vulnerable to climate change as sea level raise, and/or changes in precipitation patterns lead to various negative consequences such as reduction in agriculture yields and damages to infrastructure and to properties (Robinson 2015; Nurse et al. 2014). 
For SIDS, the impacts of rising temperatures, sea level rise, variability of rainfall patterns, and more frequent extreme weather events reaffirm the varied climatic and non-climatic vulnerabilities encountered in Island States (IPCC 2018; Robinson 2015). Given that the Indian Ocean is warming at a faster rate than any other tropical ocean region (Roxy et al. 2014), sustainable exploitation of resources within the framework of the Blue Economy will be greatly affected in the absence of proactive adaptation measures. Whereas practitioners and scientists within the adaptation landscape define adaptation differently, we focus on the definition of adaptation as utilized by the Intergovernmental Panel on Climate Change (IPCC), as an "adjustment in natural or human systems in response to actual or expected climatic stimuli or their effects, which moderates harm or exploits beneficial opportunities" (IPCC 2007).

Reducing the vulnerabilities of SIDS and Seychelles in particular is important for the sustainable development of its Blue Economy, livelihoods, human security, and environmental protection. Such actions are both urgent and timely especially at a time when the world is paying attention to the implementation of the Sustainable Development Goals. According to Nurse et al. (2014), SIDS are already experiencing a range of climate-related impacts, including increased coastal flooding and saltwater intrusion. Although its location and landmass sometimes exacerbate its vulnerability to the impacts of climate change, proactive adaptation interventions have been designed, tested, and implemented across SIDS including those of the Indian Ocean Region. These adaptation actions include rock armoring, retaining wall, groynes to ecosystem-based adaptation actions such as timber piling, beach nourishment, dune management, rainwater harvesting, and mangrove and coral restoration (Guillotreau et al. 2012). These adaptation measures are necessary, for instance, for disaster risk reduction (DRR), economic development, as well as terrestrial, coastal, and marine biodiversity conservation especially in this era of the Sustainable Development Goals (Berrang-Ford et al. 2011).

\section{Climatic and Non-climatic Induced Vulnerabilities in the Seychelles}

The Republic of Seychelles, an East African archipelago made up of 115 islands in the Indian Ocean, is one of 58 SIDS around the world. Figure 1 outlines the position of the country. This SIDS suffers from climatic and non-climatic induced vulnerabilities ranging from variability in temperatures and rainfall to anthropogenic driven vulnerabilities that are linked to dependence on climate sensitive livelihoods and economic activities.

Temperature and rainfall variability: In the Seychelles, the annual average maximum temperatures between 1989 and 2018 was estimated at $30{ }^{\circ} \mathrm{C}$ while the minimum stood at $25^{\circ} \mathrm{C}$ (Fig. 2a). Of importance to note is that the overall pattern between the maximum and minimum temperatures during the said period seems to be consistent. However, the diurnal graph (see Fig. 2b) that highlights the differences between the maximum and minimum temperatures shows a decreasing trend. This implies that the minimum temperatures are fast catching up with the maximum temperatures - an indication that the environment is getting warming over the 


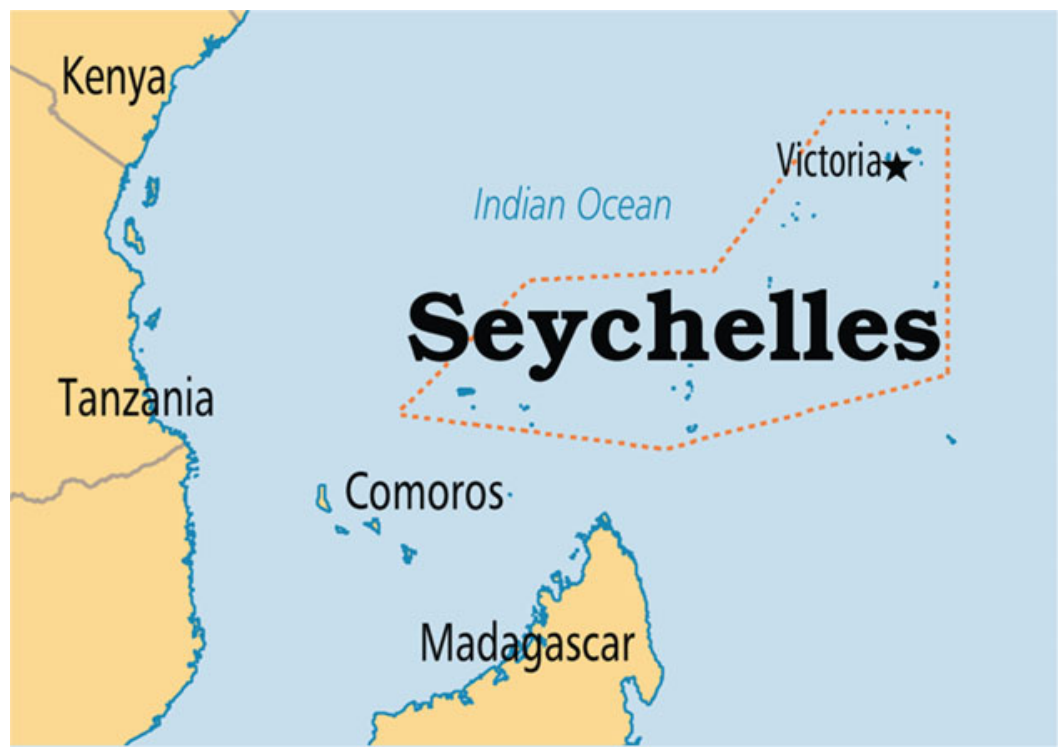

Fig. 1 Position of the Seychelles within the East African Region. Available online at https://www. google.com/search?q=map + of + seychelles + and + surrounding + countries

years. The implication of such a trend in temperature could be linked to the impacts on ecosystem good and services in the Seychelles such as the recurrent coral bleaching events, drought, flash flood, etc.

Furthermore, coral reefs, seagrass meadows, and mangroves in the Seychelles, for example, are supposed to establish a belt of coastal protection and ecosystem services along the shores. However, current manifestation of coastal vulnerabilities in the form of coastal erosion (see Table 1) reinforces the point that these protective ecosystems have been degrading fast. In the Seychelles, coral reefs have been altered over decades following mass mortality events. The most recent coral bleaching event in 2016 has caused coral mortality in the upper $15-20 \mathrm{~m}$ in average at least $70 \%$ at the Seychelles granite Islands (Wilson et al. 2012). As a result, overall reef growth is declining exposing the coasts of many Seychelles Islands to even more erosion with rising sea levels of the twenty-first century.

Rainfall patterns: Annual average figures on rainfall maximum and minimum between 1980 and 2018 in the Seychelles stood at $292 \mathrm{~mm}$ and $140 \mathrm{~mm}$ respectively (Fig. 3). An interpretation based on Fig. 3 indicate that there have been no major changes over time in terms of annual averages. In other words, the total amount of rainfall, particularly during the rainy seasons compensate for the total amount of less rainfall during the dry season. However, some incident of extreme rainfalls have been recorded in Seychelles with monthly figures equivalent to annual estimates. The most recent of such occurrence was during the last 2 weeks of May 2019 with flash flood that lasted for almost a week in some neighborhoods on Mahé Island (see Etongo 2019). According to same study, flash floods in the Seychelles is linked to 
a 32.0
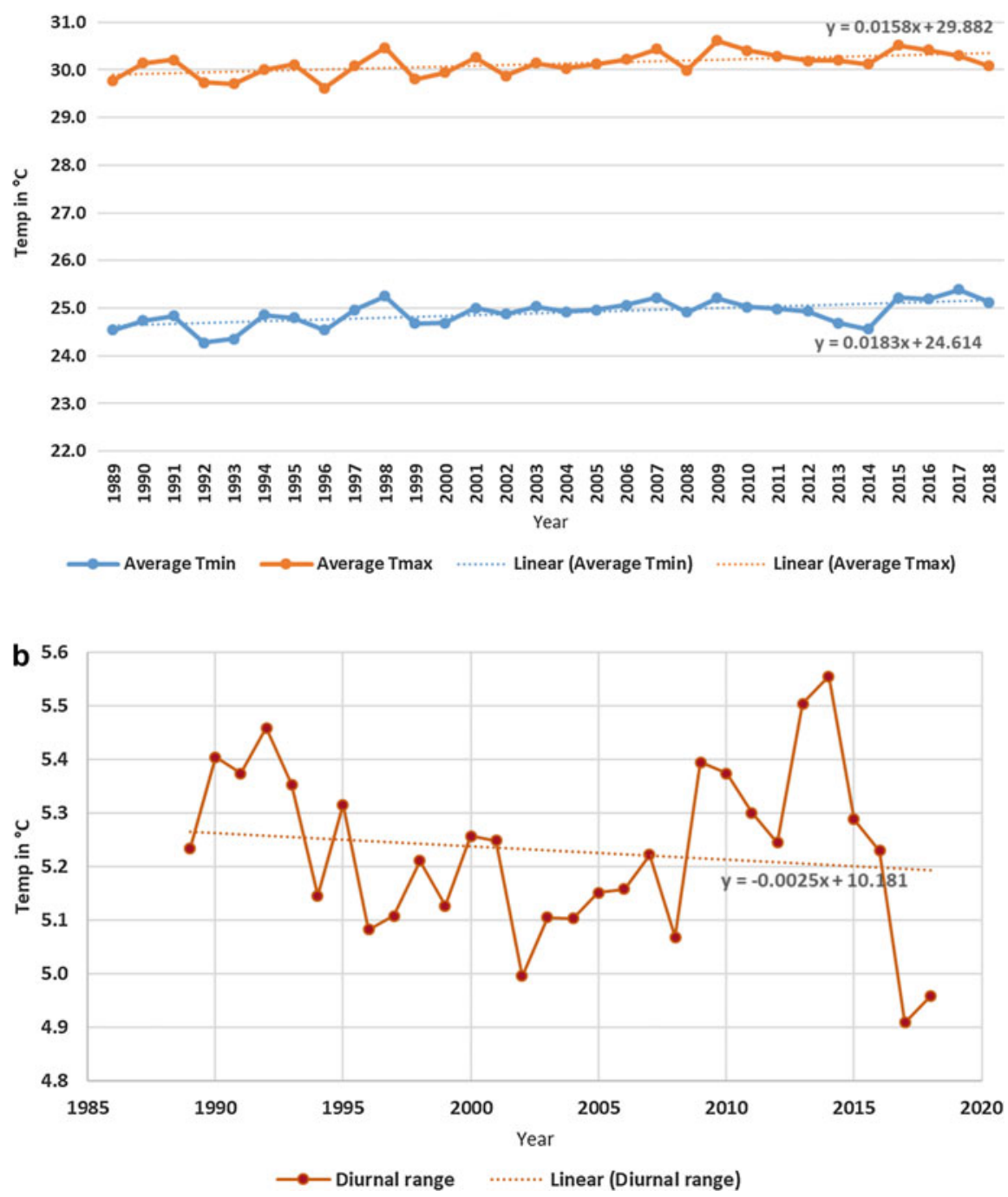

Fig. 2 (a) Average annual temperatures in the Seychelles between the years 1989 and 2018. (Source Seychelles Meteorological Authority). (b) Diurnal temperature ranges in the Seychelles between the years 1989 and 2018. (Source Seychelles Meteorological Authority)

legacy barriers to adaptation - the reclamation of wetlands for infrastructural development such as housing, resorts, roads, etc. An earlier study conducted in the Seychelles on climate change projection into 2021 indicated that the rainy seasons will be wetter and the dry seasons drier (Government of Seychelles 2009) - a clear manifestation of climate-induced vulnerability as shown in Table 1. 
Table 1 Climatic and non-climatic induced vulnerability in the Seychelles

\begin{tabular}{l|l|c|l}
\hline & Climate or climate-induced vulnerability & \multicolumn{2}{|l}{ Non-climatic induced vulnerability } \\
\hline 1 & Rainfall, precipitation, runoff & 1 & Economic, poverty \\
\hline 2 & Monsoons, storms, winds & 2 & Social, cultural \\
\hline 3 & $\begin{array}{l}\text { Temperature (air and sea surface), heat, } \\
\text { humidity }\end{array}$ & 3 & $\begin{array}{l}\text { Human activities (general), } \\
\text { recreational activities }\end{array}$ \\
\hline 5 & Storm surge, coastal inundation, flood & 4 & Pollution, waste \\
\hline 6 & Drought, dry conditions & 5 & $\begin{array}{l}\text { Population growth, demographic } \\
\text { changes }\end{array}$ \\
\hline 7 & Sea level rise, tide, wave action & 6 & Food insecurity \\
\hline 8 & Global warming & 7 & $\begin{array}{l}\text { Lack of data/information gaps/ } \\
\text { awareness }\end{array}$ \\
\hline 9 & Sater quality and/or availability, turbidity, & 8 & $\begin{array}{l}\text { Agricultural activities, soil (in) } \\
\text { fertility }\end{array}$ \\
\hline 10 & Soil/coastal erosion, landslide & 9 & Human settlement, housing \\
\hline 11 & Diseases; air-, food-, water-borne & 10 & Deforestation \\
\hline 12 & Coral bleaching/health & 11 & $\begin{array}{l}\text { Over-exploitation of resources, } \\
\text { overfishing }\end{array}$ \\
\hline 13 & Ocean acidification & 12 & Environmental degradation \\
\hline 14 & Ocean current & 13 & Land use changes \\
\hline 15 & Cloud cover & 14 & Size \\
\hline & & 15 & Location, insularity \\
\hline & & 16 & Cost of adaptation \\
\hline & & 17 & Elevation - low \\
\hline & & 18 & $\begin{array}{l}\text { Oredging, land reclamation } \\
\text { tenure arrangements }\end{array}$ \\
\hline & & 20 & Lack of insurance \\
\hline & & Limited credit availability \\
\hline & & & \\
\hline & & &
\end{tabular}

The latest country's population estimate indicates that around 98.000 people live in the country (World Bank 2019). Similar to what is observed in other SIDS, Seychelles is currently facing unprecedented threats to its viability because of the impacts of climatic and non-climatic induced vulnerabilities. The development in the Seychelles has occurred predominantly on the coastline that are vulnerable to the impacts of climate change such as sea level rise, coastal inundation, beach erosion, etc. (Rice et al. 2019). The vulnerability of the Seychelles is illustrated by the fact that it has suffered from several disasters in the last four decades, some of which are driven by climate change, while others are non-climatic (see Table 1).

Additionally, new patterns of rainfall distribution have emerged in Seychelles amidst increasing coastal development, compared to the situation two decades ago (SMA 2019). The consequences are constant flash floods that last for several days in Mahé especially during the month of May 2019. Continuous rainfall for 2-3 days wasn't a major problem some four decades ago. However, the current situation is different given the level of coastal development that has taken place especially 


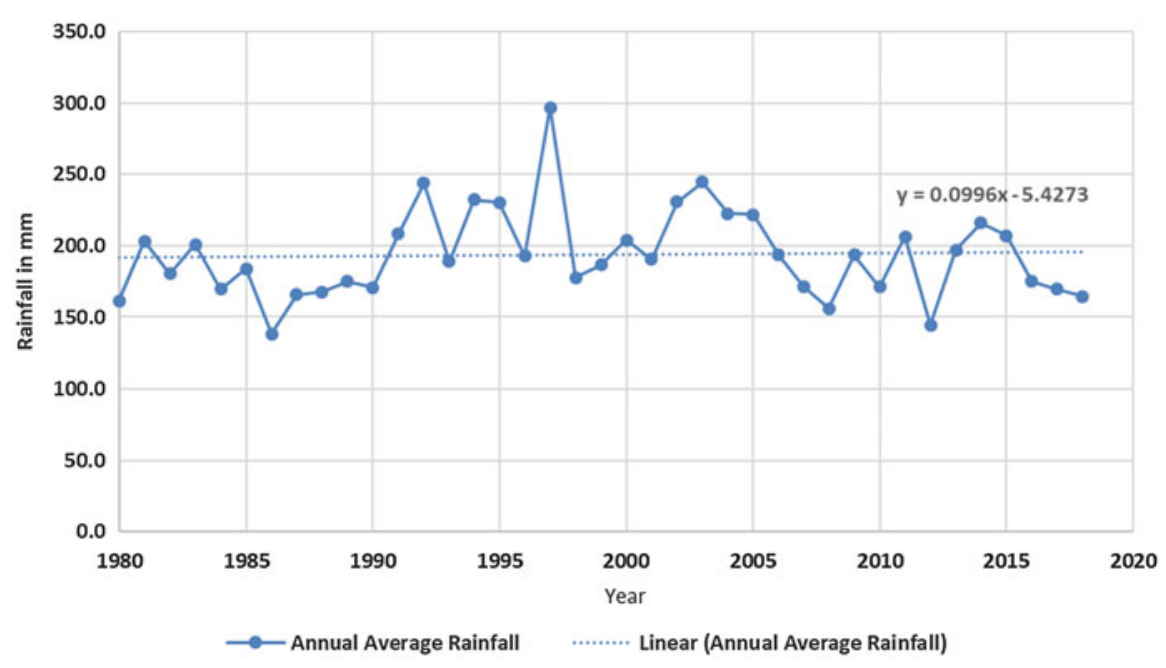

Fig. 3 Average annual rainfall in the Seychelles between the years 1980 and 2018. (Source Seychelles Meteorological Authority)

during the last decade on reclaimed wetlands whose water table is very close to the surface and may require several days for water to drain into the soil after rainfall (Etongo 2019: 45). Seychelles' vulnerability to the impacts of climate change has raised concern in four main areas, and they include sea level rise, changes in rainfall patterns, coastal flooding, and extreme weather events (Government of Seychelles 2013). Adaptation is considered a priority in Seychelles and in other SIDS as a strategy to mitigate both climatic and non-climatic driven vulnerabilities through the implementation of different adaptation actions. The next section of this chapter describes some of the adaptation interventions implemented in the Seychelles together with their pros and cons.

\section{An Overview of Adaptation Measures in the Seychelles}

A portfolio of approaches and interventions have been implemented in Seychelles, in order to adapt to the impacts of climate change. This section outlines some of them.

\section{Hard Engineering Techniques}

Hard engineering actions to adaptation in the Seychelles include highly visible, manmade structures, such as rock armoring, retaining walls, and groynes in order to protect especially the coastal and critical infrastructures such as roads, schools, hospitals, etc. (Rice et al. 2019). It is argued that hard adaptive measures involve capital-intensive, large, complex, inflexible technology, and infrastructure, whereas 

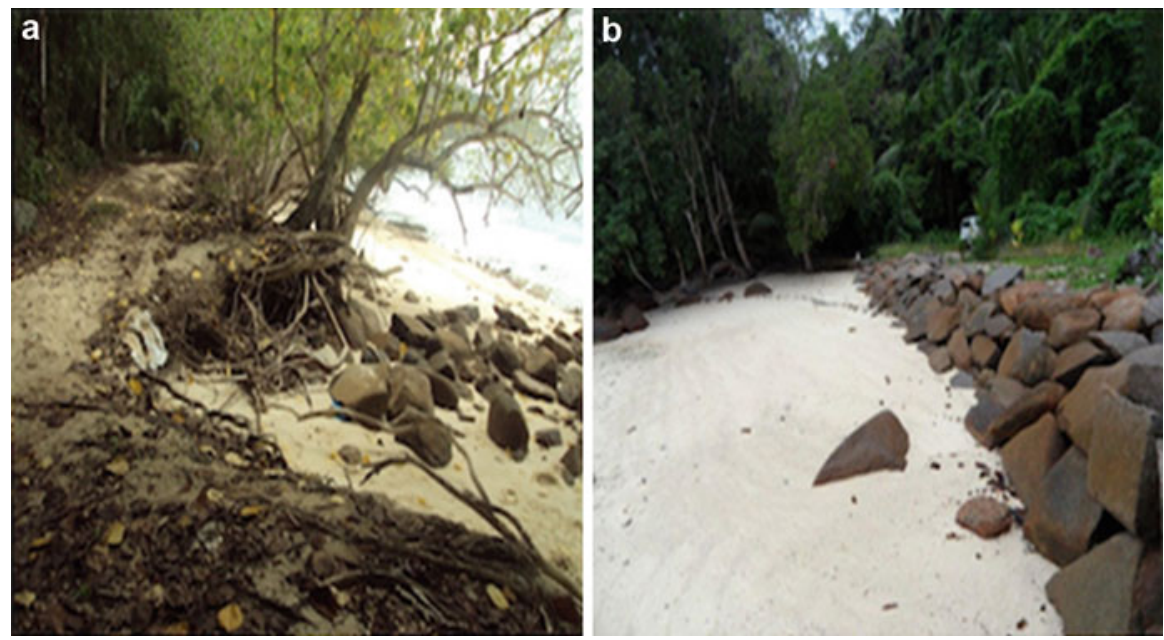

Fig. 4 Severe erosion at Anse Marie-Louise on Praslin Island highlighting coastal erosion (a) and the construction of rock armoring (b) to mitigate the impacts of coastal erosion (MEECC 2019)

soft adaptive measures prioritize natural capital, community control, simplicity, and appropriateness (Sovacool 2011). Rock armoring involves the placement of large rocks piled or placed at the foot of dunes in areas prone to erosion or in areas that have been severely eroded. A good example is the case of Anse Marie-Louise on Praslin Island (Fig. 4). Geo-textile fabric is usually placed behind and across the rock placements. The rocks absorb the wave energy and hold beach material. With time, the accretion of sand could result in the formation of new beaches (MEECC 2019).

The Seychelles' sea walls have been constructed of stone, timber piling, and rock armoring (Rice et al. 2019). Sea walls made of stone were mostly constructed during the colonial era, are low in height, and currently compromised by wave action and, therefore, rarely used today. Timber piling has been a more recently utilized strategy, and it incorporates EbA approaches such as dune restoration and replanting of native coastal vegetation. The success rate for this type of strategy is inconsistent. Most of the recent reclamation work on Mahé has been equipped with rock armoring and sea walls. Although these methods have proved to prevent coastal erosion, however, it is frequently considered an eyesore (Government of Seychelles 2017).

\section{Soft Engineering Techniques}

Soft engineering options are considered less expensive than hard engineering techniques. They are usually more long term with less impact on the environment. Examples of soft engineering adaptation actions implemented in the Seychelles include timber piling, beach nourishment, sand dune management, and the most recent being EbA. Due to their relevance, they are herewith described in turn: 


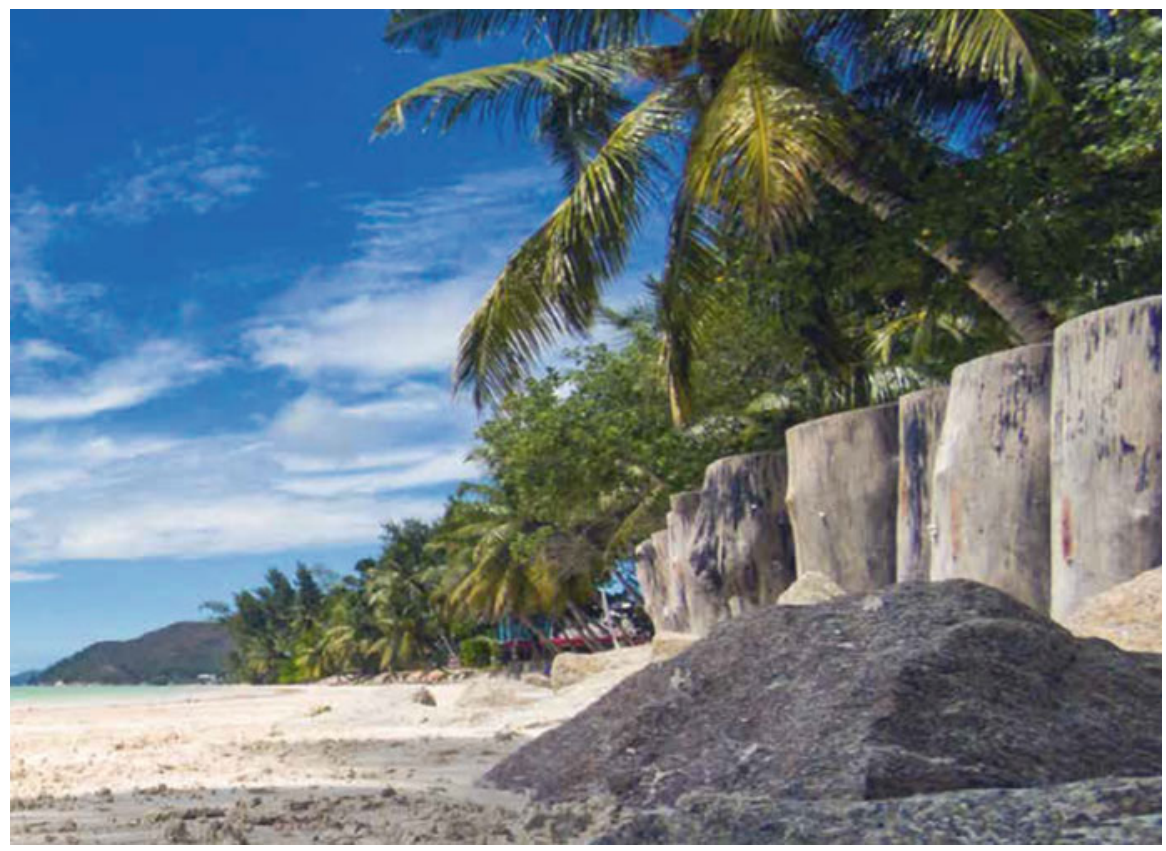

Fig. 5 Timber piling for coastal protection on Praslin Island (World Bank and MEECC 2019)

\section{Timber Piling}

This method provides a physical barrier protecting unprotected dune-land from the direct hit of surging waves as has been implemented across the Seychelles. Geo-textile fabrics are placed behind and across the length of the wooden structures to complement the wooden pilings to trap sand that is washed up with the onshore transport of sediments by wave action (see Fig. 5). Backfilling with sand is implemented to allow the dune-land to recover more quickly than it would to further stabilize dune-land restoration and stabilize timber piling (World Bank and MEECC 2019).

\section{Beach Nourishment}

Beach replenishment or nourishment is a technique used in coastal defense management schemes. It involves importing sand off the beach and piling it on top of the existing sand, and this adaptation action has been implemented at different vulnerable beaches on Mahé Island in the Seychelles (Fig. 6). The imported sand, however, must be of a similar quality to the existing beach material so that it can integrate with the natural processes occurring there without causing any adverse effects (World Bank and MEECC 2019).

\section{Sand Dune Management}

Sand dune stabilization or sand dune management is used to prevent the loss of sediment on the beach. This method has been strengthened by coastal re-vegetation whereby selected coastal plants are planted to protect the dune-land vegetation and 


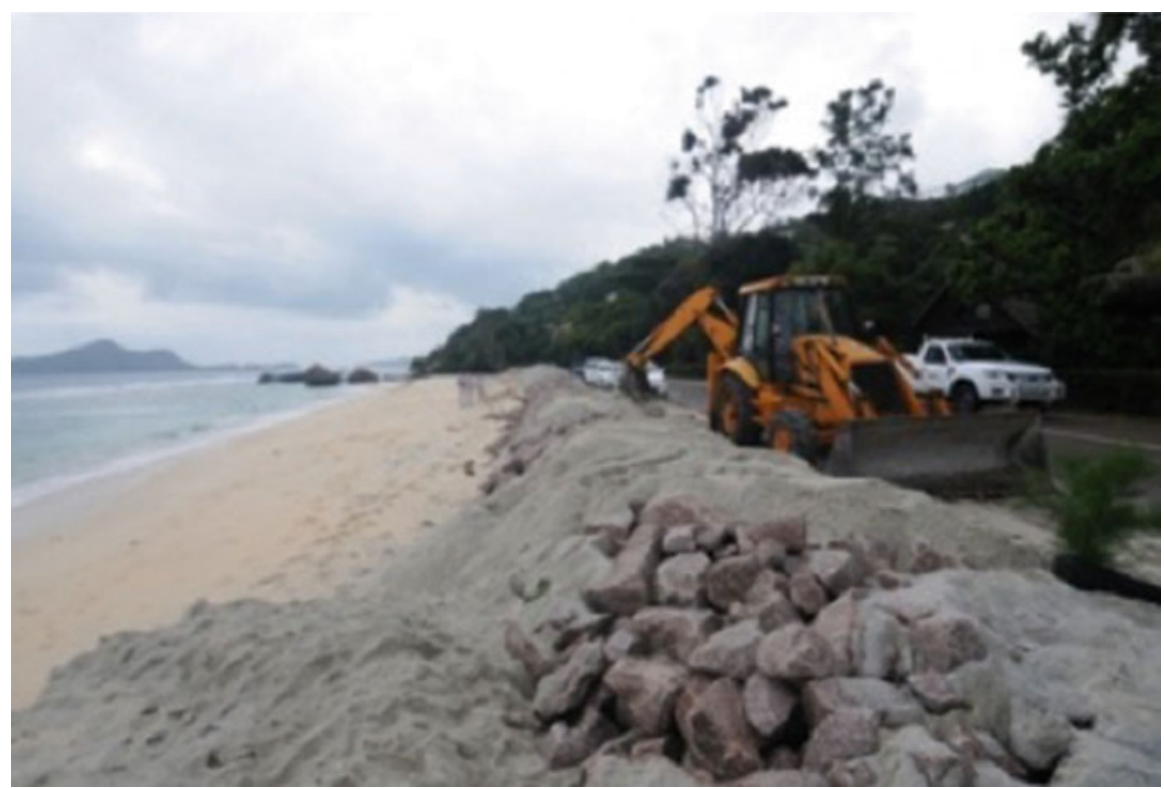

Fig. 6 Beach nourishment project at the North East Point beach, Mahé Island (MEECC 2019)

stability (Fig. 7a). The construction of boardwalks (Fig. 7b) and bollards (Fig. 7c) has helped to stop the removal of sediments by anthropogenic activities especially across some hotspot areas on the North-East Point beach on Mahé Island.

\section{Ecosystem-Based Adaptation}

Ecosystem-based Adaptation (EbA) is a set of adaptation policies or measures that consider the role of ecosystem services to respond to the adverse impacts of climate change and can be used at multiple scales and in different sectors (Munang et al. 2013). EbA initiatives just like the Ecosystem-Based Adaptation to Climate Change in Seychelles that started in 2011 supported development aspirations and adaptation objectives through the sustainable management of biodiversity and ecosystems (Khan and Amelie 2014). This project uses nature-based methods through the application of technical solutions at specific watershed and costal sites such as reinforcing access to water, reprofiling of wetlands, and mangrove restoration (see Etongo 2019: 53). Coral reef restoration is another example of EbA projects that often entails the utilization of species resistant to bleaching and is considered a promising technology in Seychelles. There has also been wetland restoration work around Port Launay, Roche Caiman, and the freshwater marsh at North East Point. This work often entails the cleaning and replanting of mangrove areas.

The EbA project is considered a win-win for climate change and livelihoods because the forests and wetlands of Seychelles granitic islands play an important role 

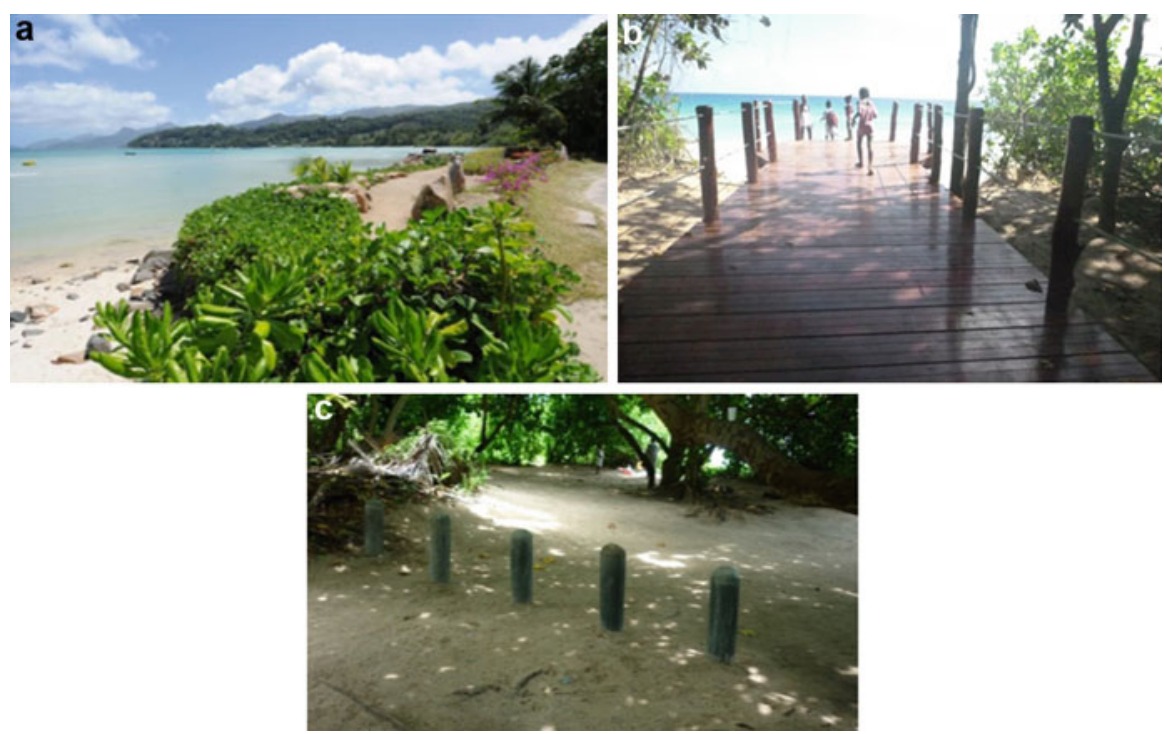

Fig. 7 Re-vegetation at Anse à La Mouche (a), constructed boardwalk at Grand Anse (b) and bollards (c) to protect dune-land from vehicles at Anse Royale (MEECC 2019)

in regulating stream flows and water quality. Forested land binds the soil, thereby decreasing soil erosion and increasing the capacity of soils to absorb and retain water. This allows water to penetrate deeper into the soil, allowing for less runoff and slower release. Wetlands and riparian vegetation also assist in reducing erosion while slowing water discharge over a longer period. The benefits include ameliorating the effects of climate change on water supplies by providing more regular stream flow during the lengthier dry season and, secondly, buffering against flooding following intense rainfall events. Similarly, mangroves and fringing coral reefs protect coastal land against coastal erosion, while coastal sand dunes and wetlands play an important role in controlling coastal flooding (UNEP 2017). All of these adaptation actions be it hard or soft that have been implemented in the Seychelles have their pros and cons as shown in Table 2.

Although some initiatives can potentially foster adaptation in the short term, there is a risk that they affect the environments', sectors', and people's long-term capacity and opportunities to cope with and manage the impacts of climate change (Magnan et al. 2016). Such a situation is considered as maladaptation. Climate change requires people to adjust ("adapt"), and the inability of persons and communities to adjust to environmental or economic instability is a part of maladaptation. Furthermore, people must be able to adapt not only to new hazards and changing resources, but also to new development initiatives, and to changes in access to and control over resources (Eriksen et al. 2015). It is therefore imperative to take stock of the adaptation actions that have taken place or are ongoing in the Seychelles given her vulnerability to the impacts of climate change. 
Table 2 Summary of the pros and cons of adaptation actions in the Seychelles

\begin{tabular}{|c|c|c|}
\hline $\begin{array}{l}\text { Adaptation } \\
\text { actions }\end{array}$ & Pros & Cons \\
\hline & \multicolumn{2}{|l|}{ Hard engineering techniques } \\
\hline $\begin{array}{l}\text { Retaining wall } \\
\text { and groynes }\end{array}$ & Protects coastal and critical infrastructure & $\begin{array}{l}\text { Very expensive to set up } \\
\text { and to maintain }\end{array}$ \\
\hline \multirow[t]{2}{*}{ Rock armoring } & $\begin{array}{l}\text { Rocks absorb the wave energy and hold beach } \\
\text { material }\end{array}$ & $\begin{array}{l}\text { Logistically difficult to } \\
\text { organize }\end{array}$ \\
\hline & \multicolumn{2}{|l|}{ Soft engineering techniques } \\
\hline Timber piling & Physical barrier protecting unprotected dune-land & $\begin{array}{l}\text { Timber may get used up } \\
\text { over time }\end{array}$ \\
\hline $\begin{array}{l}\text { Beach } \\
\text { nourishment }\end{array}$ & $\begin{array}{l}\text { Replenishment technique helpful in coastal } \\
\text { defense management }\end{array}$ & $\begin{array}{l}\text { Requires constant } \\
\text { importing of sand }\end{array}$ \\
\hline $\begin{array}{l}\text { Sand dune } \\
\text { management }\end{array}$ & Prevent the loss of sediment on the beach & $\begin{array}{l}\text { Requires careful } \\
\text { maintenance }\end{array}$ \\
\hline $\begin{array}{l}\text { Ecosystem- } \\
\text { based } \\
\text { adaptation }\end{array}$ & $\begin{array}{l}\text { Use the role of ecosystem services to respond to } \\
\text { the adverse impacts of climate change }\end{array}$ & $\begin{array}{l}\text { Needs to be combined } \\
\text { with other techniques }\end{array}$ \\
\hline
\end{tabular}

\section{Barriers to Climate Change Adaptation in the Seychelles}

There are many barriers to climate change adaptation in the country. These are:

(i) Fragile institutions and inadequate governance related to climate change

(ii) Limited scientific knowledge and understanding of how climate change impacts the country

(iii) Financial constraints in supporting adaptation strategies

(iv) Human resource capacity (Etongo 2019: 55), here exemplified by limited staff trained on climate change adaptation methods

Khan and Amelie (2014) reaffirmed that a major institutional challenge to adaptation in the Seychelles is its effective integration into development planning. Aside from financial support provided by international agencies, national funding on adaptation actions is not only limited but poorly documented. This is also a trend seen elsewhere in Africa (Leal Filho et al. 2017). A recent report on climate change expenditures across government entities in Seychelles for 2018 stood at 597,953 SCR $(\$ 43,828.52)$ of which $20 \%$ of this figure correspond to adaptation and mitigation actions implemented by a single entity - the Public Utilities Corporation (CPEIR 2019: 12-13). Such low figures on adaptation for a country like Seychelles that consider it as national priority could partly be explained as estimates that do not match actual investments or lack of information from the private sector and difficulties in accounting for climate-related expenditures on adaptation.

Scientific knowledge and understanding on climate change adaptation in the Seychelles is another barrier partly due to fragmented knowledge on adaptation, 
little investment in research related to adaptation, and also difficulties encountered in the co-production of climate information for decision-making (Etongo 2019). Decision-makers from a wide variety of professional backgrounds increasingly find that their work intersects with the subject of climate change. The level of scientific expertise required to work on complex climate change adaptation problems is quite high, and most decision-makers in the Seychelles, other SIDS, and developing countries - such as city planners, resource managers, health officials, and farmers lack a solid foundation on the science of climate change. When tasked with integrating climate information into their planning processes, decision-makers in the Seychelles and most developing countries faces two main challenges: (1) they find it difficult to know what climate information and data are best suited for a particular problem, and (2) they often perceive that climate information and data coming out of the scientific community is not usable in decisions (Briley et al. 2015).

A lack of appropriate knowledge and quality data further widens the adaptation deficit margin in Seychelles and other developing countries. This knowledge gap could be linked to the intensity of impacts that are usually beyond our range of understanding as was the case of heavy rainfall leading to flash floods that lasted for several days during the last 2 weeks of May 2019 on Mahé Island (see Etongo 2019). Furthermore, it could be the lack of technical knowledge, skills, tools, and technology and financial resources to effectively engage in proactive adaptation measures. For example, climate forecast in the Seychelles is largely based on comprehensive data collected from the airport, while such data are available in other parts of Mahé and the outer island but with lots of data gaps. Therefore, there is a growing need to improve on the early warning systems and strengthen information and decision support systems for the population in general for climate proofing in the Seychelles.

Social and cultural barriers can emerge in response to pre-existing perceptions of risk, beliefs, values, and preferences that underpin the ways individuals and societies experience, understand, and respond to climate change (Armah et al. 2015). Jones and Boyd (2011) found that socially and culturally embedded characteristics reinforce internal community structures to resist adaptation actions perceived as undesirable. Research also suggests that barriers vary according to place and culture may act as a mediating influence in resisting environmental change, particularly where change is perceived to threaten sense of belonging and place attachment (Armah et al. 2015). The role of informal institutions as barriers to adaptation in Seychelles is often ignored. Informal institutions are typically seen as the "invisible" norms that govern behavior, like customary practices or traditions and, are often embedded in a culture (Hodgson 2006). Parking of cars in the dune area across some hotspot areas on Mahé Island have led to the construction of bollards (see Fig. 7c). However, it's not feasible to construct bollards across all of these hotspot areas, and cars could be seen parked in such places especially during the weekends.

Legacy barriers are another set of adaptation barriers that are common in the Seychelles and other developing countries. According to Moser and Ekstrom (2010), the spatial/jurisdictional and temporal origin of these barriers relative to the location of the actor are important. One of the legacy barrier in the Seychelles that put to test the nation's capacity to adapt to climate change relate to land use planning in the past 
that affects drainage of rainwater (Etongo 2019). Majority of the development in Seychelles have occurred very close to the coastline either on reclaimed wetlands or at sites whose soil characteristics and/or water table is relatively high. Flash floods after heavy rainfall despite the availability of drainage systems is common in some neighborhoods in the Seychelles and is a barrier that is both remote and a legacy.

\section{Options for Overcoming Adaptation Barriers in the Seychelles}

Adaptation is a continuous process and not an outcome, and overcoming adaptation barriers could ensure proactive adaptation action that are capable of accommodating new information and or challenges linked to climate variability and change.

Climate change adaptation is not a stand-alone. Therefore, promoting synergies between adaptation and mitigation especially within the framework of EbA projects in the Seychelles has the potential of delivering a win-win solution for livelihoods and the environment. Adopting an integrated approach to community-based adaptation $(\mathrm{CbA})$ and $\mathrm{EbA}$ have gained traction over recent years among scientist,

policymakers, and development practitioners. Integrating $\mathrm{CbA}$ and EbA can also offer a cost-effective way to tackle climate change by capturing communities' knowledge and experience in dealing with climate variability and change. $\mathrm{CbA}$ is a bottom-up process that builds on local needs and capacities. It is based on human rights-based approaches that target the most vulnerable people and fully includes them in adaptation planning and implementation. It can also operate at scale, for example, through mainstreaming into government processes, but with communities remaining central to planning and action (IIED 2014). The Community Development Division in the Ministry of Local Government in the Seychelles could be used as an entry point into the various communities to improve adaptation through the integration of $\mathrm{CbA}$ and $\mathrm{EbA}$ actions.

In order to overcome the barriers that often arise during the co-production of climate information is to form direct partnerships with climate scientists to coproduce usable information for decision-making (Dilling and Lemos 2011). Collaboration between decision-makers and climate scientists offers an opportunity to leverage expertise from both parties to better serve problem-solving. Highly iterative interactions between decision-makers and scientists contribute to greater societal outcomes. The Seychelles National Climate Change Committee offers such platform for collaboration with the participation of a wide range of stakeholders from government, non-governmental organizations, research institutions, private sector, and community-based organization. However, this type of relationship requires a large investment of time, and the number of decision makers working on climate problems is much greater than the number of available partnering climate scientists (Bidwell et al. 2012).

Cross-sectoral and institutional collaboration is another option in overcoming most of the adaptation barriers that are institutionally driven. Collaboration across sectors will avoid the duplication of projects and improve on the efficient use of the limited financial resources nationally available for adaptation. Ford and Berrang-Ford (2014) are of the opinion that overcoming such barriers would require 
consistency, comparability, comprehensiveness, and coherency which they described as the 4Cs of adaptation tracking. The University of Seychelles offered a three-day short course in July 2019 on the topic mainstreaming climate change adaptation into development planning. This course provided a platform for different stakeholders to gain knowledge on mainstreaming adaptation into policy, across sectors and within projects. Additionally, the Global Climate Change Alliance $(\mathrm{GCCA}+)$ Seychelles have provided several trainings on climate change across different institutions in Seychelles during the last 2 years. The most recent was a training on early warning system that took place in the month of August 2019 at the Seychelles Meteorological Authority (SMA) office.

Furthermore, the very first climate change policy for the Seychelles and the Third National Communication to the UNFCC offers another opportunity to improve climate change adaptation in the country. A proactive climate policy should be coherent with other national development strategies. Some of these strategies are Seychelles Sustainable Development Strategy, National Communications in addition to Seychelles National Disaster Management Policy, and various legal mandates on environmental protection such as the Environmental Management Plan among others. Informal institutions that are rooted in culture or way of life might require new ways of doing things or a change in behavior in order to improve the adaptive capacity of Seychelles. A very good example in the Seychelles is the parking of cars in the dune area. Creating car parks in specific areas where land is available and convenient could partly address this problem. On the other hand, a wheel clamp policy could be implemented for those parking their cars in the dune area across different hotspots in the Seychelles. Institutional capacities, in particular measures of good governance such as participation, rule of law, accountability, transparency and responsiveness, etc., are the strongest predictors of national adaptation policy in the Seychelles and elsewhere (Berrang-Ford et al. 2014).

The role of local knowledge in adaptation to climate change is invaluable in reducing the vulnerabilities of communities to the impacts of climate change. However, there are concerns over its relevance for future adaptation amidst other challenges. Evidence from a study conducted in Tanzania suggests that local knowledge may contribute to adaptation to climate change in a number of ways especially when integrated with scientific knowledge (Naess 2013). Local knowledge especially among the fishing folks in the Seychelles is an important knowledge system that could be document. Local indicators of climate change impacts based on local knowledge have the potential to improve our understandings of how climate change affects the environment and the blue economy in the Seychelles. The fishing folks interact with the ocean space frequently and have accumulated local knowledge that could feed into early warning systems.

Finally, remote/legacy barriers are those barriers that are most difficult to address in the "here and now," as the locus of control is elsewhere and the origin of the barrier in the past. The three dominant types of such barriers include institutional ones such as the existing or missing governance structure and laws, economic and funding issues (such as the global economic crisis or state budget cuts), and attitudinal issues (the public's attitude, awareness and understanding of climate change, or longstanding personality conflicts). Since the year 2015 of its existence, 
Seychelles' Conservation and Climate Adaptation Trust (SeyCCAT) have provided financial support nationally for several research projects and small businesses in Seychelles related to climate change. Therefore, intervention in this case is remedial and compensatory by local actors: those who can and those who take it upon themselves "to break eggs" in order to make "omellette" - a view supported by Ekstrom and Moser (2014).

\section{Conclusions}

Several actions have been taken to improve climate change adaptation in Seychelles such as hard and soft engineering and policy options. These actions include policy development and revision, institutional setup, rock armoring, bollards, retaining walls, mangrove and coral restoration, rainwater harvesting, EbA approaches, human resource capacity development, research, education, and outreach. Despite such efforts to reduce the vulnerability of the Seychellois population to the impacts of climate change, several barriers hamper the adaptation process. Chief among these barriers include institutional and governance issues, scientific knowledge and understanding, financial issues, and human resource capacity. Adaptation actions are likely to be hindered by poor governance which in some cases is not limited to formal but also to informal institutions that are linked to cultural belief systems or a way of life. Parking of cars in the dune areas are "invisible" norms that govern behavior like customary practices or traditions often embedded in a culture.

Some proposed strategies to overcome these barriers include promoting synergies between adaptation and mitigation into sectorial policies and national development. Collaboration across institutions should be enhanced to avoid duplication of projects and also to share resources and expertise. In order to overcome barriers that often arose during the co-production of climate information is to form direct partnerships with climate scientists to co-produce usable information for decision-making. Furthermore, the community development division under the Ministry of Local Government should serve as an entry point to promote the integration of $\mathrm{CbA}$ and EbA actions across all the districts in the Seychelles. This will not only re-invent the wheel but will also harness local knowledge systems that are fast eroding while strengthening community participation in a bottom-up approach in the fight against the impacts of climate change. The role of technology transfer could solve some of the legacy problems and lesson could be learned from the Netherlands on what types of drainage systems to construct given that the water table in some locations in the Seychelles especially on Mahé Island is very close to the surface.

\section{References}

Armah FA, Luginaah I, Hambati H, Chuenpagdee R, Campbell G (2015) Assessing barriers to adaptation to climate change in coastal Tanzania: does where you live matter? Popul Environ 37 (2):231-263 
Berrang-Ford L, Ford JD, Paterson J (2011) Are we adapting to climate change? Glob Environ Chang 21:25-33

Berrang-Ford L, Ford JD, Lesnikowski A, Poutiainen C, Barrera M, Heymann SJ (2014) What drives national adaptation? A global assessment. Climate Change 124:441-450

Bidwell D, Dietz T, Scavia D (2012) Fostering knowledge networks for climate adaptation. Nat Clim Chang 3:610-611

Briley L, Brown D, Kalafatis SE (2015) Overcoming barriers during the co-production of climate information for decision-making. Clim Risk Manag 9:41-49

Climate Public Expenditure and Institutional Review (CPEIR) (2019) Part 3: expenditures review. The global climate change alliance plus initiative. The Republic of Seychelles

Dilling L, Lemos MC (2011) Creating usable science: opportunities and constraints for climate knowledge use and their implications for science policy. Glob Environ Change Hum Policy Dimens 21:680-689

Ekstrom JA, Moser SC (2014) Identifying and overcoming barriers in urban climate adaptation: case study findings from the San Francisco Bay Area, California, USA. Urban Clim 9:54-74

Eriksen SH, Nightingale AJ, Eakin H (2015) Reframing adaptation: the political nature of climate change adaptation. Glob Environ Chang 35:523-533. https://doi.org/10.1016/j. gloenvcha.2015.09.014

Etongo D (2019) Climate change adaptation in Seychelles: actors, actions, barriers and strategies for improvement. Seychelles Res J 1(2):43-66

Ford JD, Berrang-Ford L (2014) The 4Cs of adaptation tracking: consistency, comparability, comprehensiveness, Coherency. Mitig Adapt Strat Glob Change. https://doi.org/10.1007/ s11027-014-9627-7

Government of Seychelles (2009) Seychelles National Climate Change Strategy. The Seychelles National Climate Committee, Victoria, Seychelles

Government of Seychelles (2013) Seychelles damage, loss, and needs assessment 2013 floods. A report by the Government of Seychelles. With support from the EU, UN, and World Bank. Victoria, Seychelles

Government of Seychelles (2017) Seychelles technology needs assessment report - adaptation. Ministry of Environment, Energy and Climate Change, Victoria, Mahe Island, Republic of Seychelles

Guillotreau P, Campling L, Robinson J (2012) Vulnerability of small island fishery economies to climate and institutional changes. Curr Opin Environ Sustain 4:287-291

Hodgson GM (2006) What are institutions? J Econ Issues XL(1):1-25

IIED (2014) Ecosystem- and community-based adaptation: learning from natural resource management. The International Institute for Environment and Development (IIED), London. Available online at http://pubs.iied.org/17243IIED

IPCC (2007) Climate change 2007: synthesis report. Contribution of working groups I, II and III to the fourth assessment report of the intergovernmental panel on climate change (ed: Core Writing Team, Pachauri RK Reisinger A). IPCC, Geneva, 104pp

IPCC (2018) Summary for policymakers. In: Global warming of $1.5^{\circ} \mathrm{C}$. an IPCC special report on the impacts of global warming of $1.5^{\circ} \mathrm{C}$ above pre-industrial levels and related global greenhouse gas emission pathways, in the context of strengthening the global response to the threat of climate change, sustainable development, and efforts to eradicate poverty. World Meteorological Organization, Geneva. Retrieved from https://report.ipcc.ch/sr15/pdf/sr15_spm_final.pdf

Jones L, Boyd E (2011) Exploring social barriers to adaptation: insights from Western Nepal. Glob Environ Chang 21(4):1262-1274

Khan A, Amelie V (2014) Assessing climate change readiness in Seychelles: implications for ecosystem-based adaptation mainstreaming and marine spatial planning. Reg Environ Chang. https://doi.org/10.1007/s10113-014-0662-4

Leal Filho W, Belay S, Kalangu J, Menas W, Munishi P, Musiyiwa K (eds) (2017) Climate change adaptation in Africa- fostering resilience and capacity to adapt. Springer, Cham

Magnan AK, Schipper ELF, Burkett M, Bharwani S, Burton I, Eriksen S, Gemenne F, Schaar J, Ziervogel G (2016) Addressing the risk of maladaptation to climate change. WIREs Clim Change. https://doi.org/10.1002/wcc.409 
Ministry of Environment, Energy and Climate Change (2019) Use of soft and hard engineering approaches to coastal zone protection in Seychelles. Available online at http://www.meecc.gov. sc/index.php/what-we-do/coastal-protection-management/

Moser SC, Ekstrom JA (2010) A framework to diagnose barriers to climate change adaptation. Proc Natl Acad Sci 107:22026-22031

Munang R, Thiaw I, Alverson K, Mumba M, Liu J, Rivington M (2013) Climate change and ecosystem-based adaptation: a new pragmatic approach to buffering climate change impacts. Curr Opin Environ Sustain 5:67-71

Naess LO (2013) The role of local knowledge in adaptation to climate change. WIREs Clim Change 4:99106. https://doi.org/10.1002/wcc.204

Nurse LA, McLean RF, Agard J, Briguglio LP, Duvat-Magnan V, Pelesikoti N, Tompkins E, Webb A (2014) Small islands. In: Barros VR et al (eds) Climate change 2014: impacts, adaptation, and vulnerability part B: regional aspects contribution of working group II to the fifth assessment report of the intergovernmental panel on climate change. Cambridge University Press, Cambridge/New York, pp 1613-1654

Rice H, Rolf B, Rumschlang J, Xie D (2019) Evaluating the impacts of sea level rise and storm surges on Seychelles' critical infrastructure. School for Environment and Sustainability, University of Michigan, Michigan

Robinson S (2015) Climate change adaptation trends in small island developing states. Mitig Adapt Strat Glob Change. https://doi.org/10.1007/s11027-015-9693-5

Roxy MK, Ritika K, Terray P, Masson S (2014) The curious case of Indian Ocean Warming. J Clim 27:8501-8509

Scandurra G, Romano AA, Ronghi M, Carfora A (2018) On the vulnerability of Small Island developing state: a dynamic analysis. Ecol Indic 84:382-392

Seychelles Meteorological Authority (2019) New patterns of rainfall distribution are emerging in Seychelles compared to two decades ago. https://www.meteo.gov.sc/\#/newsDetails. Accessed 28 Aug 2019

Sovacool BK (2011) Hard and soft paths for climate change adaptation. Clim Pol 11(4):1177-1183

UNEP (2017) Terminal evaluation of the UN environment project 'Building capacity for coastal ecosystem-based adaptation in Small Island developing states'. Evaluation Office of UN Environment, Nairobi

United Nations Conference on Environment and Development (UNCED) (1992) Rio de Janeiro, Brazil, 3-14 June 1992 - AGENDA 21

Wilson SK, Graham NAJ, Fisher R, Robinson J, Nash K, Chong-Seng K, Polunin NVC, Aumeeruddy R, Quatre R (2012) Effect of macroalgal expansion and marine protected areas on coral recovery following a climatic disturbance. Conserv Biol 26(6):995-1004

World Bank Group (2019) Seychelles. World Bank Open Data, Washington, DC

World Bank, Ministry of Environment, Energy and Climate Change of Seychelles (2019) Seychelles Coastal Management Plan: 2019-2024. World Bank/Ministry of Environment, Energy and Climate Change of Seychelles, Washington, DC/Victoria

Open Access This chapter is licensed under the terms of the Creative Commons Attribution 4.0 International License (http://creativecommons.org/licenses/by/4.0/), which permits use, sharing, adaptation, distribution and reproduction in any medium or format, as long as you give appropriate credit to the original author(s) and the source, provide a link to the Creative Commons license and indicate if changes were made.

The images or other third party material in this chapter are included in the chapter's Creative Commons license, unless indicated otherwise in a credit line to the material. If material is not included in the chapter's Creative Commons license and your intended use is not permitted by statutory regulation or exceeds the permitted use, you will need to obtain permission directly from the copyright holder.

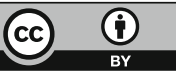

